UCRL-ID-120878

\title{
Evaluation of Beryllium Exposure Assessment and Control Programs at AWE, Cardiff Facility, Rocky Flats Plant, Oak Ridge Y-12 Plant and Lawrence Livermore National Laboratory
}

\author{
J.S. Johnson \\ K.L. Foote \\ J.W. Slawski \\ G.C. Cogbill
}

June 1995

This is an informal report intended primarily for internal or limited external distribution. The opinions and conclusions stated are those of the author and may or may not be those of the Laboratory.

Work performed under the auspices of the U.S. Department of Energy by the Lawrence Livermore National Laboratory under Contract W-7405-Eng-48. 


\section{DISCLAIMER}

This document was prepared as an account of work sponsored by an agency of the United States Government. Neither the United States Government nor the University of California nor any of their employees, makes any warranty, express or implied, or assumes any legal liability or responsibility for the accuracy, completeness, or usefulness of any information, apparatus, product, or process disclosed, or represents that its use would not infringe privately owned rights. Reference herein to any specific commercial product, process, or service by trade name, trademark, manufacturer, or otherwise, does not necessarily constitute or imply its endorsement, recommendation, or favoring by the United States Government or the University of California. The views and opinions of authors expressed herein do not necessarily state or reflect those of the United States Government or the University of California, and shall not be used for advertising or product endorsement purposes.

This report has been reproduced directly from the best available copy.

Available to DOE and DOE contractors from the Office of Scientific and Technical Information P.O. Box 62, Oak Ridge, TN 37831

Prices available from (615) 576-8401, FTS 626-8401

Available to the public from the National Technical Information Service

U.S. Department of Commerce

5285 Port Royal Rd.

Springfield, VA 22161 


\section{DISCLAIMER}

Portions of this document may be illegible in electronic image products. Images are produced from the best available original document. 


\section{Evaluation of Beryllium \\ Exposure Assessment and Control Programs \\ at \\ AWE, Cardiff Facility, \\ Rocky Flats Plant, \\ Oak Ridge Y-12 Plant, and \\ Lawrence Livermore National Laboratory}

Phase I Report

April 28, 1995

James S. Johnson and Ken L. Foote

Fission Energy and Systems Safety Program

Lawrence Livermore National Laboratory

Livermore, CA 94551

James W. Slawski

Defense Programs

U.S. Department of Energy

Washington, DC

Graham Cogbill

Atomic Weapons Establishment

Cardiff Facility, United Kingdom 


\section{Acknowledgment}

We wish to thank the may people and organizations that contributed their time and historical resources to this project. George Campbell from the Hazards Control Department of Lawrence Livermore Laboratory provided his historical perspective on Be handling procedures and practices which was very useful in designing this investigation. From the DOE Rocky Flats Field Office, Dr. Janet Torma-Krajewski, Gary Noss and Anthony Barnard provided Be program information. Lee Ann Holwager, Dr. Joseph Furman, Tom Szdlowski and Mike Richen provided the available Be program information on Rocky Flats from the EG\&G operational perspective as well as conducted facility tours. At the Oak Ridge Y-12 visit Don Hoag from the DOE Field Office provided some background information. Martin Marietta contractor information on $\mathrm{Y}-12$ and facility tours were provided by Gary Bean, James L. Jenkins and Dr. L. Gail Littlefield. Information about the Lawrence Livermore Laboratory Be control program was provided by Rohit Shaw, Kyle Griggs, Joe Lipera, Jerry Cohen and Rob Hadley. During our visit to AWE Cardiff facility, Graham Jones was indispensable in providing detailed information and facility tours of their many operations. Carol Watson, Cary Gellner and Linda Achziger took turns providing the clerical support to prepare this document and Irene Hedman provided her editing expertise. 


\section{Table of Contents}

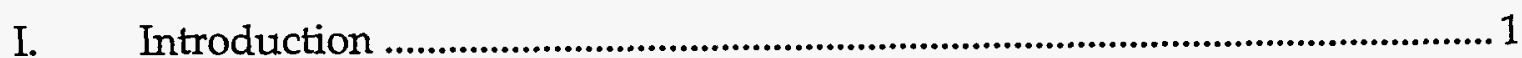

II. Site Visit to Rocky Flats Plant .................................................................... 2

III. Site Visit to Oak Ridge Y-12 Plant ...............................................................3

IV. Site Visit to Lawrence Livermore National Laboratory …............................. 4

V. Site Visit to UK, AWE Cardiff Facility ..........................................................6

VI. Status of the Cardiff's Beryllium Air-Sampling Database............................. 8

VII. Preliminary Evaluation of Cardiff Foundry Workers

Beryllium Exposure Data ..............................................................................9

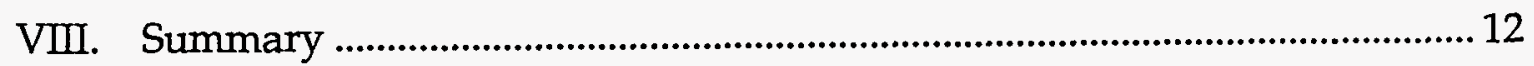

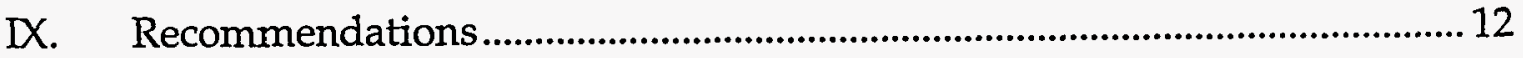

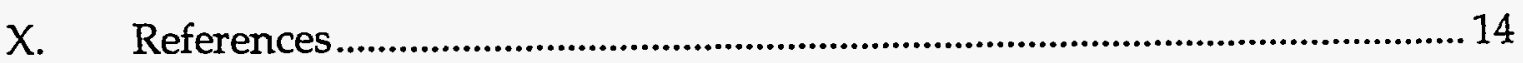




\section{Introduction}

Overexposure to Be can cause acute disease in some employees and, in a smaller percentage of employees, chronic beryllium disease (CBD). ${ }^{1}$

Since the mid-1940s, the Atomic Energy Commission (AEC), the Energy Research and Development Agency (ERDA), and the Department of Energy (DOE) contractors have widely used beryllium (Be). In 1949, the AEC implemented a standard that established workplace practices and airborne levels to adequately control employee exposure to Be. This standard is still being used as the basis for the current Occupational Safety and Health Administration (OSHA) Be standard.

Recent advances in immunogenetics have permitted the initial development of an experimental Be Lymphocyte Proliferation Test (LPT) that is much more sensitive than the traditional CBD chest $x$-ray/clinical symptoms diagnosis. This test has been used to identify a significant number of new CBD cases among employees in DOE industrial hygiene Be control programs, eg. Rocky Flats and Oak Ridge Y-12 Plant. ${ }^{2}$

A critical element in understanding the increase in CBD cases among these employees is the accurate reconstruction (or estimate) of their.exposure to Be. Unfortunately, actual personal sampling was not widely carried out until the mid-1980s. In addition, during the period of the largest Be use (1950 to mid-1980), crude estimates were made of worker exposure to Be and therefore they are inaccurate. These inaccuracies will have a significant effect on the application of the Be LPT to the diagnosis of CBD. Thus, more accurate methods of estimating historic Be worker exposure need to be developed. The adequacy of the current $\mathrm{Be}$ standard is also difficult to evaluate because of the lack of adequate Be exposure data.

Site visits were made to the Rocky Flats Plant (29-31 March 1994), the Oak Ridge Y-12 Plant (14-15 April 1994), the AWE Cardiff Facility (9-13 May 1994), and LLNL (18-19 August 1994) to identify and gather exposure data for evaluation. Preliminary findings of this evaluation were presented to the BMS 18 August 1994. Another site visit was made to the Rocky Flats Plant 30 June-1 July 1994 to work with Anthony E. Barnard, a DOE Industrial Hygiene Graduate Fellow completing a summer internship at the facility, to develop a project protocol for an in-depth analysis of the use and monitoring of Be at the plant. ${ }^{3}$

The United Kingdom (UK) Atomic Weapons Establishment (AWE) Cardiff Facility has a large exposure assessment database that contains the results of many thousand static (area), personal, and surface wipe samples. As part of a joint investigative project by the DOE and AWE, Graham Cogbill (manager of Health Physics and Safety) arranged a site visit to the Cardiff facility to evaluate their sampling program and data for further study. Details of this evaluation were made available to the Joint Working Group (JOWOG) on Be and discussed with the Beryllium Monitoring Subcommittee (BMS) of the Defense Program's Be Coordinating Committee. It was agreed to keep the BMS subcommittee informed of the progress of this project. 
A multi-phase approach was used to organize and manage the project. In Phase I, available historic information was gathered, evaluated, and summarized for Be exposure assessment and control programs at the Rocky Flats Plant, Oak Ridge Y-12 Plant, and Lawrence Livermore National Laboratory (LLNL.) (The time frame for this evaluation was from facility start up to approximately 1985, that is, before major changes in DOE contractor Be control programs were made because of an increase in diagnosed CBD cases at Rocky Flats.) The most easily accessable data however, was found to be from the early 1970's to 1985. Almost all DOE contractor Be air sampling data, during this time period, is based on area sampling. A similar historic analysis was also carried out on the extensive personal, area, and surface Be monitoring program at the AWE Cardiff Facility. The results from this analysis will be used to determine if additional study of Cardiff's Be monitoring program should be undertaken in Phase II.

\section{Site Visit to Rocky Flats Plant}

The Rocky Flats Plant was the main facility in the United States that fabricated Be into various components for nuclear weapons for the AEC, ERDA, and DOE. During high-production years, the facility processed as much as several metric tons of Be and required up to three work shifts in the machine shop area-depending on production requirements. Various beryllium production and development activities were carried out in 36 different buildings, 28 of which contained actual work areas; 8 contained exhaust plenums. The major Be fabrication activities, however, were performed in two machine shops (Rooms 106 and 107) in Bldg. 444. (Refs. 4-8).

Throughout the operation of these machine shops, several types of local exhaust ventilation control systems were used: individual exhaust systems were used on lathes and mills in late 1950s and early 1960s; a centralized exhaust system with interior cyclone-chip collectors and particle filters was used in the mid-1960s through the mid-1970s; and a centralized exhaust system with an exterior collection/filter system was used from the mid-1970s and beyond. Most of the local exhaust system enclosures only surrounded the machine chuck and part, rather than the entire working area of the mill or lathe. The Heller saw used for the initial cutting of Be stock material was completely enclosed; operators were required to wear respirators.

The exhaust system used in the mid-1970s had the potential to achieve a more effective and uniform velocity (between 300-350 fpm), but foreign objects drawn into it caused individual exhaust hoses to clog. In addition, the Be hood exhaust velocity was not routinely monitored and it was also common practice to turn off the air flow when a hood was not in use. This has made it difficult to evaluate the performance of any hood because the air flow is influenced by the number of hoods in operation. A high-velocity, low-volume exhaust system was added to supplement the existing exhaust system as part of the initial reaction to the first few cases of CBD. 
From 1969-1975, the Rocky Flats Plant used a foundry process in Bldg. 444 that consisted of casting operations. Beryllium-rolling operations were performed in Bldg. 883 until 1985. These operations were very dirty and required implementation of a variety of temporary control measures (e.g., respiratory protection) including the use of safety glasses, coveralls, underwear, and safety shoes for all full-time Be workers. It was also routine practice for workers to shower at the end of the work day before changing into their regular clothes.

To measure the effectiveness of Be controls, samples were collected from breathing zone, fixed air-head locations and from flat surface swipes in the production facility. The fixed air-head sampling system operated at a flow rate of approximately $50 \mathrm{l} / \mathrm{min}$ and used Whatman 41 cellulose filter paper. The central vacuum source for the system made air-flow adjustments difficult because adjustment to one head influenced the flow to the adjoining heads. The flow calibration was performed once a month by the radiation technicians assigned to the area. Sampling of dry surface swipes of $1-\mathrm{ft}^{2}$ areas was performed on a specific schedule, with a minimum number of samples specified and adjusted depending on the work load. Measurements were made during a 24-hour period using an 8-hour value in order for the calculation to represent a conservative approach.

Beryllium analyses are currently being performed at the Rocky Flats Plant using a nitric-acid digestion, followed by programmed heating to a dry ash. The remaining residue is dissolved in nitric acid; the resultant solution is analyzed by atomic absorption (AA) spectroscopy. As best as can be determined, a similar procedure using AA is the only analytical method that has been used at the Rocky Flats Plant.

The chemistry laboratory at Rocky Flats has never been accredited by the American Industrial Hygiene Association (AIHA), but it has participated on the BMS Be round-robin program without any significant problems. This laboratory has an internal quality control program that analyzes 30 Be-spiked filter papers a month. To obtain quicker results, a neutron activation system was developed and routinely used since 1986 to analyze swipe samples within 15-20 min of collection. Since 1989, however, all Be personal samples have been sent offsite to an accredited AIHA laboratory for analysis.

\section{Site Visit to Oak Ridge Y-12 Plant}

The need to control Be exposure at the Y-12 Plant was recognized early during initial design and fabrication activities. Gary Bean, a senior industrial hygienist who has worked at the plant since 1976 in various industrial hygiene technical and management positions, provided copies of the early Be control program for our review. ${ }^{9-17}$

With management's support, Mr. Bean and several other industrial hygienists maintained a strict and consistent Be control program. It required specific areas for Be processing; personnel controls; local exhaust ventilation to minimize dust exposure; utilization of the experience, procedures and 
information used for thorium and uranium fabrication; and a limited number of facilities in which Be could be handled. In 1970, BeO operations were moved from Bldg. 9766 to Bldg. 9201-5 (Alpha 5) in the modified Butler building where a specific BeO shop was set up adjoining the east machine shop. Depleted uranium and occasional Be fabrication jobs were routinely carried out in the east machine shop. The majority of the BeO work was carried out in the upgraded Butler building.

Local exhaust ventilation and an integrated hooded enclosure were provided for each machine in the $\mathrm{BeO}$ shop, and a mineral-oil-based coolant was used throughout the entire machining operation. The majority of Be processed at this Plant was beryllium oxide (BeO), which was hot-pressed into shapes that were machined into the final precision parts. Finished parts were removed from the machines, coated with oil, dipped into a cleaning solution, and wrapped in a plastic bag before leaving the shop area. These parts were cleaned again, smeared by an industrial hygiene technician, and their cleaning confirmed before they were released for dimensional inspection. Quarterly air-flow surveys were carried out by the Maintenance and Engineering Group that designed the exhaust enclosures and support systems. The ventilation was spot checked by the shop supervisor using a hot-wire anemometer; the exhaust velocity of each hood in use was confirmed at the beginning of each shift; and the floors in the machine shop were routinely wet mopped after each shift.

Using Whatman 41 smear tabs, dry surface samples were collected routinely on $1-\mathrm{ft}^{2}$ areas until the early $1980 \mathrm{~s}$ when the sample area was changed to $100 \mathrm{~cm}^{2}$. Fixed-head sampling was carried out by placing the samplers that operated continuously at a rate of $201 / \mathrm{min}$ in the approximate breathing zone of machinists. The filters were changed bi-weekly during active work periods. Initially, these samples were analyzed using a DC arc spectrograph that had a reported sensitivity to Be of $0.01 \mu \mathrm{g}$. This system was improved in 1961 by adding a pelletizer for sample preparation. By 1987, the analytical method was changed to the more sensitive inductively coupled plasma (ICP) mass spectrometer. The analytical laboratory used to analyze the samples is AIHA accredited; results from the BMS Be round-robin program indicate no significant Be analysis problems.

Sampling records for the area and surface results are available as far back as the 1950s. A computer record of area and fixed-head samples taken in the early 1960 s was initiated as part of the radiation monitoring program.

The Y-12 Plant has a union workforce that has a series of job titles from which Be workers can be identified. Thus, it is possible to identify which machinist(s) worked on a specific machine, the part he/she ran, the material machined, and the length of time it took to complete the process.

\section{Site Visit to Lawrence Livermore National Laboratory}

Since 1952, Be has always been treated as a controlled material at LLNL. Specific requirements (including engineering and monitoring controls) were 
established for the purchase, use, shipment, and disposal of Be and fabrication activities were restricted to a limited number of facilities. Most Be fabrication activities were carried out in Bldg. 321, which was specifically designed for contamination control. This building contained change rooms; controlled work areas; a workplace sampling system; and enclosed and ventilated lathes, mills, and other fabrication tools. The ventilation system was designed to remove the airborne aerosol and particulates from the machine enclosures and pass the contaminated air through high-efficiency particulate air (HEPA) filters that removed the Be before it was discharged to the environment.

In addition, a separate facility was established in Bldg. 241 to carry out metallurgical experiments on $\mathrm{Be}$ and compounds such as $\mathrm{BeO}$. For the most part, these experiments were carried out in specially designed glove boxes and glove box lines. Local exhaust ventilation was provided for all Be operations that were HEPA-filtered before the Be was discharged to the environment. Change rooms, area monitoring, and work controls were also used when the program mainly involved $\mathrm{Be}$ and $\mathrm{BeO}$ activities.

"Pluto" was a major program undertaken at LLNL in the late 1950s. This program involved the use of significant quantities of $\mathrm{BeO}$ that were blended with support materials, extruded, and high fired to produce ceramic parts that were assembled into a ram jet nuclear reactor. Production operations for the program were carried out in Bldgs. 166 and 169, assembly operations in Bldg. 243, and machining and pressing operations in Bldg. 231. Other experimental activities involving Be powder metallurgy were performed in these facilities as well. HEPA-filtered local exhaust ventilation, personnel controls, and area monitoring were used to minimize Be exposure.

Further details on Be engineering control requirements can be found in the 1963 and 1979 documents entitled "Safe Handling of Beryllium and Its Compounds." 18-19

The Laboratory recognized the toxicity of Be in 1952, and developed health and safety documentation on how to safely handle and use Be and its compounds. ${ }^{20}$ The responsibility for overseeing the use of Be was initially assigned to an industrial hygienist in the Medical Department but was later transferred to the Industrial Hygiene Group when it was formed as part of the new Hazards Control Department in 1958. Documentation was also developed specifying the requirements for the design of local exhausts, Be control velocities equivalent to the particulate velocity at the point of origin, as well as for welding operations ( $500 \mathrm{ft} / \mathrm{min}$ ). Enclosures and air-cleaning devices (e.g., HEPA filters) were required for any operation that produced airborne Be contaminants. Specific open-area exhaust velocities of 300 cubic feet per minute per square foot $\left(\mathrm{cm} / \mathrm{ft}^{2}\right)$ were specified for dry operations and $150 \mathrm{cfm} / \mathrm{ft}^{2}$ for wet operations. Implementation of these criteria was a previous responsibility of the Industrial Hygiene Group but is now a shared function of staff from Facility Engineering, the experimental program, and the Hazards Control Department. Measurement of the control velocities is now carried out by the ES\&H team supporting the Laboratory program. 
The effectiveness of the Be control program at LLNL was monitored by taking area air samples and surface swipes, and airborne particulate samples from other general areas. The area samples were taken using a portable air sampler with an adjustable filter-head height that was placed at specific work operations and at heights that approximated the workers breathing zone. This sampler operated 7 days a week, 24 hours a day, at an initial sampling rate of $4 \mathrm{~cm}$ and used $10.3 \mathrm{~cm}$ diameter Whatman 41 filter paper. The paper was changed daily, Monday through Friday. The current sampler operates at $1 \mathrm{cfm}$ because of the change to a smaller air-sampling head $\left(2.9 \mathrm{~cm}\right.$ in diameter) ${ }^{21}$

Dry surface swipes of $100 \mathrm{~cm}^{2}$ from specific locations determined by the program industrial hygienist were routinely collected. Air and surface samples were analyzed using a sulfuric/nitric- and perchloric-acid dissolving process, followed by fluorometric analysis based on Morin dye. In mid-1977, however, this method was replaced by atomic absorption (AA) spectroscopy. An ICP mass spectrometer was purchased in 1988 and used to analyze some samples that required more sensitivity.

\section{Site Visit to the UK, AWE, Cardiff Facility}

The AWE Cardiff Facility was initially a Royal Ordnance Factory where the fabrication of Be started in 1961 and continues to today. It has metallurgical capabilities for melting and casting, powder production, impact milling, ball milling, hot-pressing, isostatic-pressing, and heat and surface treatment. ${ }^{22}$ From the late $1970 \mathrm{~s}$ to the mid-1980s, approximately $7,000-10,000 \mathrm{lb}$ of Be a year were processed in this facility - a volume that has declined gradually in 1992 to approximately $1000 \mathrm{lb}$. Very little $\mathrm{BeO}$ was processed at the facility.

This facility is equipped with offices, change rooms, Be process and handling areas, machine shops, laboratories, and mechanical equipment rooms. The local ventilation system is designed so that air flows from the office area to the change rooms, down a central hallway, and through the various process and laboratory areas. This technique of directing air flow from clean areas through contaminated process areas before passing through the air cleaning device is a recognized standard control method in building design for toxic and radioactive materials. Air entering the facility passes through a roughing filter and a HEPA filter. Each Be processing machine is either partially or completely enclosed and exhausted through the local ventilation system, which has a double stage of HEPA filters. The velocity through the machine enclosure open areas is kept at $50 \mathrm{ft} / \mathrm{min}$. In 1976 a new machine shop; mechanical equipment room; and a highvelocity, low-volume exhaust system with a capture rate that ranges from 6000$8000 \mathrm{fpm}$ (depending on the application) were added to the facility.

The air flow of the local exhaust system was surveyed periodically by the Safety Department until 1993, when a formal testing and maintenance program was implemented. An outside contractor who specializes in ventilation design, testing, and maintenance is now responsible for servicing the system. 
The effectiveness of the facility's engineering and personnel controls has been routinely monitored since 1961 by personal air-sampling, static (area) air sampling, and surface swipes. Each person who enters the Be work area is issued a Casella personal sampling pump (Model AFC123I) that operates at a sampling rate of $21 / \mathrm{min}$. and uses 37-mm diameter Whatman 41 filter paper. Static air samples are collected with a Negretti Automation L30 series air sampler that operates at a sampling rate of $30-361 / \mathrm{min}$. and uses $60-\mathrm{mm}$ diameter Whatman 41 paper. Individual air samplers are used for the static air sampling system, rather than a centralized system with one large pump.

The facility has various areas where surface wipes are taken routinely. During Cardiff's peak Be processing times, it was not unusual to collect 70 static samples, 70 personal samples, and 100 surface wipes each day. Samples of surface areas of approximately $1000 \mathrm{~cm}^{2}\left(\approx 1 \mathrm{ft}^{2}\right)$ are taken with the dry wipe (90-mm diameter Whatman 542 paper). The specific sample location in the designated area is detailed as part of the sample collection process.

Sixty-one permanent areas were selected for static sampling, 13 of which are identified as core samples. Core samples are changed at mid-day and at the end of each day. The mid-day core samples are analyzed the same day they are changed to provide more timely Be results on the workplace air and to quickly implement corrective actions, if necessary. The static air samples are changed by the safety technician at the end of the day and analyzed the following day. Pump calibration is carried out on a less routine basis by an electronics technician using equipment recommended by the manufacturer for the personal and static pumps.

Static samplers that operate at sampling rates of 60 and $1001 / \mathrm{m}$ are also available for special applications and emergency situations.

The analytical laboratory is capable of analyzing a total of 300 Be samples per day. Samples were analyzed using a spark spectrograph before 1976 and an atomic adsorption (AA) spectrometer from 1976 to present. In early 1991, an ICP mass spectrometer was purchased and is now used to achieve better Be sensitivity on certain samples. Filter paper dissolution uses a standard sulfuric acid/nitric acid process and an additional hydrofluoric acid-dissolving process for solid samples. No formal quality assurance program using spiked blind samples has been implemented to date. The laboratory has participated in the BMS Be round-robin program since it started with no significant problems identified.

Beryllium was recognized as a toxic material during the design phase of the facility. Thus, strict engineering and personnel controls were developed and implemented to protect the health of workers. Workers are provided with a complete change of clothing when working in the Be area. The laundry for contaminated clothing and respirators is conveniently located next to the change room. Eating, drinking, smoking, and bathroom breaks require leaving the Be work area, changing shoes, and washing hands, as a minimum. Workers also must wear a half-mask or full-face mask respirator equipped with a HEPA filter for operations that require additional levels of protection. Over the past 20 years, very few changes have been made to these controls. 
During peak production times, approximately 100 people worked at the Cardiff Facility. The workforce at Cardiff now stands at about 40; turnover is low because of the high desire for employment at the facility. This union workforce has skilled and non-skilled jobs. The job titles are general and do not offer any potential for use to identify and classify Be workers.

\section{Status of Cardiff's Beryllium Air-Sampling Database}

For our preliminary analysis, the Cardiff Be air-sampling database ${ }^{23}$ was converted into a Macintosh database using the program Foxbase. The original data, as provided to LLNL, was stored in 164 text files on 14 IBM-formatted diskettes. Each data record was stored in a single test string and had to be converted (in Excel) to tab-delimited text for use by the Macintosh database program. The static data files had missing header information that complicated the conversion. We can easily and quickly sort, evaluate the Be exposure data, and print a variety of summary reports (e.g., total records for a given field) from the Macintosh database.

All the Cardiff Be air-sampling data are now stored in two Foxbase databases: one for the static data and another for the personal data. The static database has 10 searchable fields (year, day, location, sample, duration, flow1, flow2, time, mass, and concentration). It contains 158 different static locations within the Cardiff Facility and 290,971 records that occupies $11 \mathrm{Mb}$ of disk space. The personal database has 6 searchable fields (year, day, employee, sample, department, and mass) and contains 190,000 exposure records on 242 employees at Cardiff over the past 15 years. The overall database contains air-sampling data from January 1981 to May 1994.

Preliminary data evaluation, further analysis, and refinement of Cardiff's database are necessary. For example, a simple analysis of the upper and lower limits of the database revealed some questionable values. Cardiff is aware of this discrepancy and is trying to determine if the data in question is valid. Upon completing a detailed verification of the database, future work should involve comparison of personal exposure data and static sampling data. A first step would be to more accurately calculate personal exposure concentrations, which are currently calculated using an 8-hour exposure time and are not usually reflective of the situation because shift hours vary from 4-10 hours each day. Upon making these corrections, the static data can be matched directly with the personal data so that a paired $t$-test can be performed to determine how well the two measurements correlate. 


\section{Preliminary Evaluation of Cardiff Foundry Workers Beryllium Exposure Data}

We have evaluated the work experience at the Cardiff Facility for various routine tasks and agreed that the best worker-population personnel sampling records to initially evaluate were those from the Foundry. This evaluation was carried out to determine the number of personal samples available for each worker and the range of Be workplace concentrations measured. We also were interested in evaluating these data to determine if they were log normally distributed. We identified 9 Foundry workers and assembled the summary information in Table 1 for each worker from the Cardiff database at LLNL. We also sorted the data by mass to better categorize the worker's exposure levels (see Table 2).

Table 1. Summary of Be personal sampler data for Cardiff Foundry workers from January 1981-May 1994.

\begin{tabular}{|c|c|c|c|c|}
\hline $\begin{array}{c}\text { Cardiff } \\
\text { employee } \\
(\text { LLNL ID \#) }\end{array}$ & $\begin{array}{c}\text { Number } \\
\text { of records }\end{array}$ & $\begin{array}{c}\text { Total mass } \\
\text { observed } \\
(\mu \mathrm{g})\end{array}$ & $\begin{array}{c}\text { Average } \\
\text { mass per record } \\
(\mu \mathrm{g})\end{array}$ & $\begin{array}{c}\text { Maximum } \\
\text { mass observed } \\
(\mu \mathrm{g})\end{array}$ \\
\hline 1 & 1,357 & $2,474.70$ & 1.82 & 160 \\
\hline 2 & 1,274 & $2,154.10$ & 1.69 & 272 \\
\hline 3 & 1,475 & $1,966.20$ & 1.33 & 171.5 \\
\hline 4 & 1,220 & $1,818.90$ & 1.49 & 31.4 \\
\hline 5 & 2,980 & $1,605.10$ & 0.54 & 38.3 \\
\hline 6 & 849 & $1,204.10$ & 1.42 & 48.8 \\
\hline 7 & 1,652 & $1,244.00$ & 0.75 & 47.9 \\
\hline 8 & 1,334 & $3,155.30$ & 2.37 & 52.9 \\
\hline 9 & 1,465 & $1,199.70$ & 0.82 & 345.1 \\
\hline & 13,607 & $16,822.10$ & 1.82 & \\
\hline
\end{tabular}


Table 2. Expanded summary data from Be personal sampler data for Cardiff Foundry workers from January 1981 - May 1994.

\begin{tabular}{|c|c|c|c|c|c|c|}
\hline \multirow{2}{*}{$\begin{array}{c}\text { Employee } \\
(\text { LLNL } \\
\text { ID\#) }\end{array}$} & $\begin{array}{c}\text { mass }=0.0 \\
(\mu \mathrm{g})\end{array}$ & $\begin{array}{c}\text { mass }=0.1 \\
(\mu \mathrm{g})\end{array}$ & $\begin{array}{c}\text { mass }<1 \\
(\mu \mathrm{g})\end{array}$ & $\begin{array}{c}\text { mass }>=1 \\
(\mu \mathrm{g})\end{array}$ & $\begin{array}{c}\text { mass }>=10 \\
(\mu \mathrm{g})\end{array}$ & $\begin{array}{c}\text { mass }>=100 \\
(\mu \mathrm{g})\end{array}$ \\
\hline 1 & 132 & 72 & 836 & 487 & 32 & 2 \\
\hline 2 & 80 & 91 & 864 & 379 & 30 & 1 \\
\hline 3 & 82 & 195 & 1,028 & 418 & 28 & 1 \\
\hline 4 & 100 & 36 & 697 & 511 & 12 & 0 \\
\hline 5 & 485 & 545 & 2,583 & 389 & 8 & 0 \\
\hline 6 & 104 & 32 & 524 & 316 & 9 & 0 \\
\hline 7 & 219 & 276 & 1,410 & 226 & 16 & 0 \\
\hline 8 & 47 & 133 & 629 & 651 & 54 & 0 \\
\hline 9 & 254 & 557 & 1,352 & 101 & 10 & 2 \\
\hline & 1,503 & 1,937 & 9,923 & 3,478 & 199 & 6 \\
\hline
\end{tabular}

To protect the identify of Cardiff Be workers, LLNL assigned a new identification number to each worker. The Be personal monitoring data for a Cardiff worker (identified as No. 4 by LLNL) was plotted to determine if these data were log normally distributed (see Fig. 1). Similarly, we also obtained data for an area sampler (identified as No. 220 in the Cardiff sampling plan) in the Foundry.work area to evaluate how these data were distributed (see Fig. 2). Both analyses found the data to be log normally distributed, but further analysis will be necessary before a similar statement can be made about the two complete data sets in the Cardiff database.

From preliminary analysis of the Cardiff database at LLNL, we have demonstrated the utility further analysis will provide. Evaluations of typical Be fabrication tasks will provide valuable ranges of potential exposure. The relationships between personal and area samples can also be accurately evaluated because of the size of the data sets and the details available on each sample. It is important to remember, however, that these data do not represent the actual exposure of a Cardiff worker to Be because half-mask and full-face mask respirators were worn while many of the personal samples were collected. 


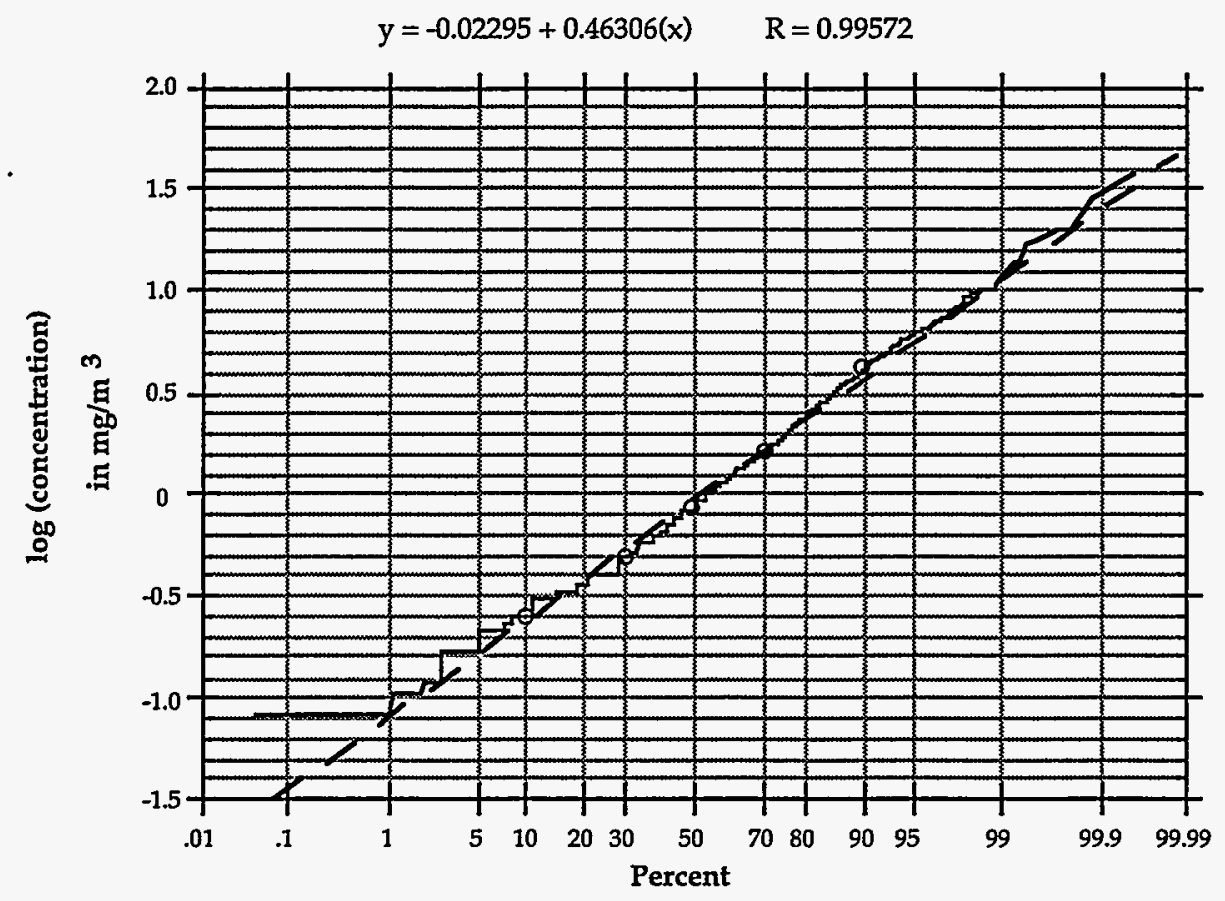

Figure 1. Plot of $\log$ (concentration) in $\mathrm{mg} / \mathrm{m}^{3}$ of personal Be air samples for Cardiff Foundry employee, LLNL ID No. 4 , versus cumulative percent.

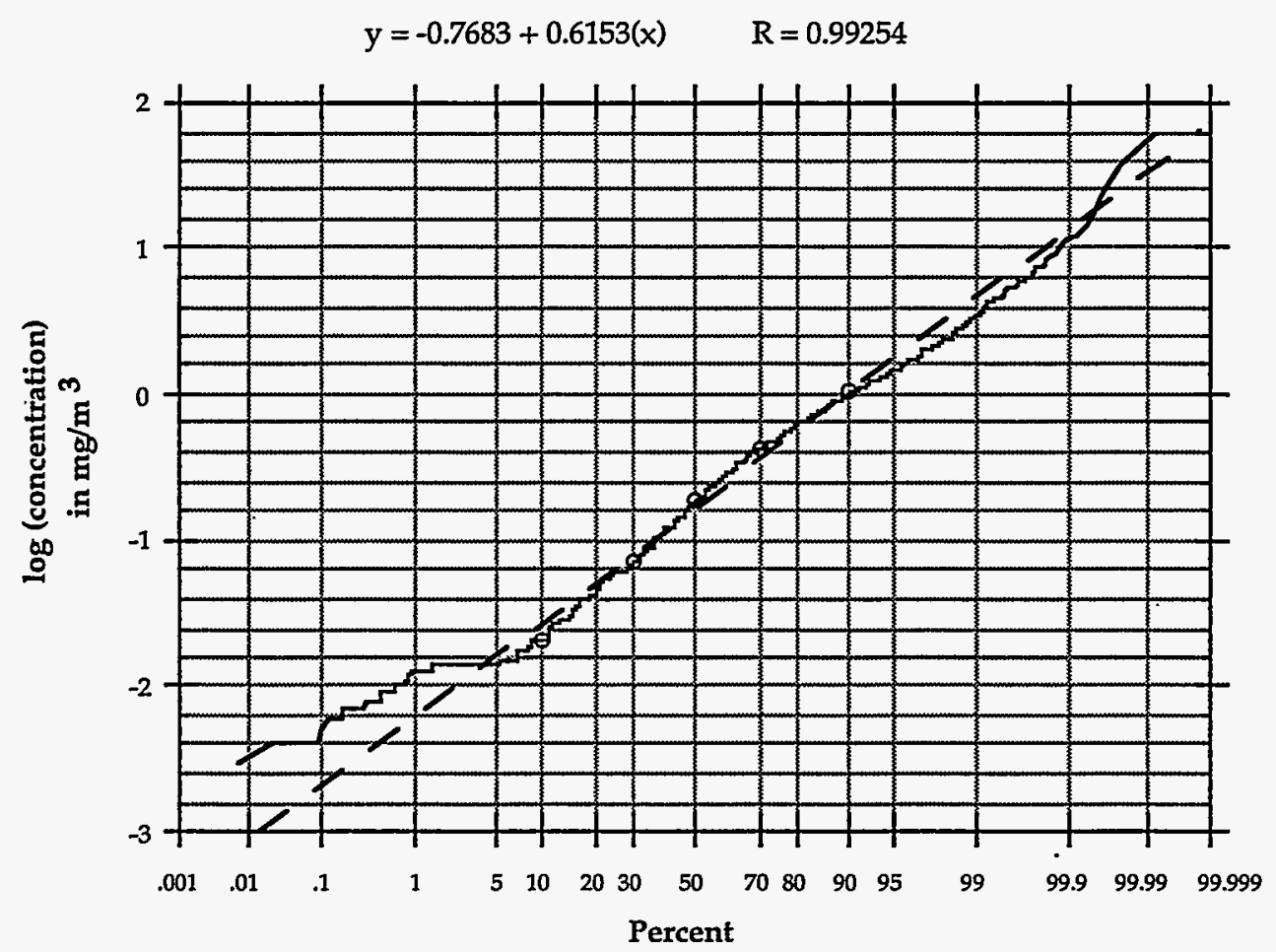

Figure 2. Plot of $\log$ (concentration) in $\mathrm{mg} / \mathrm{m}^{-} \pm$of fixed area sampler No. 220 in the Cardiff Beryllium Foundry facility versus cumulative percent. 


\section{Summary}

Site visits were made to DOE beryllium handling facilities at the Rocky Flats Plant; Oak Ridge Y-12 Plant, LLNL; as well as to the AWE Cardiff Facility. Available historical data from each facility describing its beryllium control program were obtained and summarized in this report. The AWE Cardiff Facility computerized Be personal and area air-sampling database was obtained and a preliminary evaluation was conducted. Further validation and documentation of this database will be very useful in estimating worker Be exposure as well as in identifying the source potential for a variety of Be fabrication activities.

Although all of the Be control programs recognized the toxicity of Be and its compounds, their established control procedures differed significantly. The Cardiff Facility, which was designed for only Be work, implemented a very strict Be control program that has essentially remained unchanged, even to today. LLNL and the Oak Ridge Y-12 Plant also implemented a strict Be control program, but personal sampling was not used until the mid 1980s to evaluate worker exposure. The Rocky Flats plant implemented significantly less controls on beryllium processing than the three previous facilities. In addition, records were less available, management and industrial hygiene staff turned over regularly, and less control was evident from a management perspective.

\section{Recommendations}

The only major DOE/DP contractor that has fabricated significant quantities of Be but has not been evaluated is the Los Alamos National Laboratory. To provide DP with a complete assessment of its major contractors who handled Be, we recommend a similar evaluation of this Laboratory be completed.

The one week visit to the AWE Cardiff Facility and follow up correspondence has provided a good foundation to begin the Phase II analysis. An additional site visit should be made to obtain more detailed information on the overall Be control program, machining operations, engineering controls, machinery personal and area sampling policies and procedures and medical department information on employee exposure.

The quick transfer of the Cardiff personal and area Be air-sampling database to LLNL has permitted its staff to reformat the files and carry out a preliminary evaluation of the data. LLNL Human Subjects Committee review and approval of the proposed use of the sampling data from Cardiff and other DOE contractors should be obtained. To better document the work practices, workplace conditions, and medical surveillance program that existed when these air-sampling data were collected, an expanded dialogue with the Cardiff health and safety staff should be initiated immediately because the facility is scheduled to close in two years. In addition, the Cardiff database should be updated with last year's data and the inconsistencies in various parts of the data sets resolved. Further analysis of the data should be carried out after changes to the database 
are complete. Correlation of the personal and area sampling results described in this report should be completed, and typical workplace concentrations for various fabrication activities calculated.

Representative fixed-head Be air sampling data from Oak Ridge Y-12 and Rocky Flats should be obtained, evaluated, and compared with the Cardiff data to determine if the workplace air concentrations during Be operations are similar. Typical fabrication operations carried out at all the facilities evaluated should be identified and compared to one another and, if possible, the personal data available from Cardiff operations should be linked to DOE fabrication operations. As part of the source analysis process, care should be taken to identify particle size, morphology, and oxide content whenever possible. This information may prove to be valuable in evaluating employee exposure and $\mathrm{CBD}$ incidence.

An update on the information gathered at our four site visits and the recommendations outlined in this section were presented to the BMS 28 February -1 March 1995 in Gaithersburg, MD. The BMS reviewed these recommendations and suggested that the study continue into Phase II. Information gathered in this phase will help DP to better document Be contractor workplace activities and Be airborne concentrations so that they can construct the work history of employees diagnosed with CBD. 


\section{References}

1. Eisenbud, M. and L. Lisson, Epidemiological Aspects of Beryllium-Induced Non malignant Lung Disease: A 30-Year Update, JOM, 25(3), 196-202 (1983).

2. Kreiss, K., et al., "Epidemiology of Beryllium Sensitization and Disease in Nuclear Workers," Am Rev Respir Dis., 148, 985-991 (1993).

3. Barnard, Anthony E., Beryllium Exposure Assessment in Building 444, The Department of Energy's Rocky Flats Environmental Technology Site, DOE, Rocky Flats Office (August, 1994).

4. U.S. Department of Energy Operations Office, Beryllium Disease Case at. Rocky Flats Plant, Golden, Colorado, DOE, Albuquerque NM, no number assigned, (October 1984).

5. Zavor, P.L., Beryllium Shop Air Sampling Evaluation for Rockwell International, Occusafe, Inc., Wheeling, IL, 7555/8138A (February 22, 1985).

6. Zavor, P.L., Beryllium Shop Ventilation System and Work Practices, Independent Evaluation for Rockwell International, Occusafe Inc., Wheeling, IL, 8032/9194A, (December 11, 1985).

7. Zavor, P.L., Beryllium Air Sampling Data Statistical Evaluation for Rockwell International, Occusafe, Inc., Wheeling, IL, 8146/4093B (February 27, 1987).

8. Mahaffey, J. M., Location of Beryllium Areas (Historical/Present), Interoffice Correspondence, EG\&G, Rocky Flats, Inc., Golden, CO, JWM-154-93 (November 11, 1993).

9. Case, J. M., E. R. Walkens, and F. S. Jones, MTR Beryllium Machining History, Carbide and Carbon Chemicals Company, A Division of Union Carbide and Carbon Corporation, Y-12 Area, Oak Ridge, TN, Report No. Y-868, (April 22, 1952).

10. Union Carbide Corporation, Beryllium Processing at the Oak Ridge Y-12 Plant, Oak Ridge Y-12 Plant, Oak Ridge, TN, (November 1964).

11. Industrial Hygiene Guidelines-Beryllium Control Areas, Change House Facilities and Procedure, Union Carbide Internal Correspondence, Oak Ridge Y-12 Plant, Oak Ridge, TN (November 10, 1970).

12. The Materials Laboratory Operating Health Procedure (Room 333), Development Division Hazardous Operations Procedure Safety Standard, Oak Ridge Y-12 Plant, Oak Ridge, TN, 1.10.2 (June 12, 1972). 
13. Beryllium, Y-12 Plant, Standard Practice Procedure, Oak Ridge Y-12 Plant, Oak, Ridge, TN, 35 (March 30, 1973).

14. Union Carbide Corporation, Alpha 5 East Machine Shop, Health and Safety Procedures, Oak Ridge Y-12 Plant, Oak Ridge, TN, 9201-5E (June 5, 1975).

15. Union Carbide Corporation, 9201-5 East Machine Shop Be Coolant System, Security, Plant Protection and Utilities Division, Utilities Administration Operating Procedure, Oak Ridge Y-12 Plant, Oak Ridge, TN, 50-50-UA-115 (June 18, 1980).

16. Martin Marietta Energy Systems, Inc., Plant Beryllium Protection Program, Health and Safety, Oak Ridge Y-12 Plant Procedures, Oak Ridge Y-12 Plant, Oak Ridge, TN, 70-201 (October 30, 1987).

17. Martin Marietta Energy Systems, Inc., Beryllium/Beryllium Oxide, Fabrication Division, Alpha-5 East Shop-Operating, Oak Ridge Y-12 Plant Procedures, Oak Ridge Y-12 Plant, Oak Ridge, TN, 50-2Y-01-001 (July 13, 1989).

18. Lawrence Radiation Laboratory, Hazards Control Manual, "Safe Handling of Beryllium and Its Compounds," Part I, Nr. 408, LRL, Livermore, CA, 408 (October 31, 1963).

19. Lawrence Livermore National Laboratory, Hazards Control Manual, Supplement 21.10, "Safe Handling of Beryllium and Its Compounds," LLNL, Livermore, CA, M-010 (May 15, 1979).

20. Lawrence Radiation Laboratory, Accident Prevention Manual "Handling and Use of Beryllium or Beryllium Compounds," LRL, Berkeley and Livermore, Livermore, CA, 284 (1952).

21. Lindeken, C. L. and O. L. Mladors, The Control of Beryllium Hazards, JAIHA, 21(3), 245-251 (1960).

22. Atomic Weapons Establishment Cardiff, The Beryllium Facility, AWE Cardiff Plant, Cardiff, UK (1980).

23. Cogbill, G. and P. Busher, AWE Cardiff, Safety and Health Physics Data for 1992, AWE Cardiff Plant, Cardiff, UK (1992). 